Article

\title{
Assessment of Volatile Compounds Evolution, Antioxidant Activity, and Total Phenolics Content during Cold Storage of Pomegranate Beverage Fermented by Lactobacillus paracasei K5
}

\author{
Ioanna Mantzourani ${ }^{1, *}$, Stavros Kazakos ${ }^{1}$, Antonia Terpou ${ }^{2} \mathbb{D}$, Athanasios Mallouchos ${ }^{3} \mathbb{D}$, \\ Athanasios Kimbaris ${ }^{1}$ (D), Athanasios Alexopoulos ${ }^{1}$, Eugenia Bezirtzoglou ${ }^{1}$ and Stavros Plessas ${ }^{1}$ \\ 1 Laboratory of Microbiology, Biotechnology and Hygiene, Faculty of Agriculture Development, \\ Democritus University of Thrace, 68200 Orestiada, Greece; stkazak@yahoo.gr (S.K.); \\ kimparis@agro.duth.gr (A.K.); alexopo@agro.duth.gr (A.A.); empezirt@agro.duth.gr (E.B.); \\ splessas@agro.duth.gr (S.P.) \\ 2 Food Biotechnology Group, Department of Chemistry, University of Patras, GR-26504 Patras, Greece; \\ aterpou@upatras.gr \\ 3 Laboratory of Food Chemistry and Analysis, Department of Food Science and Human Nutrition, \\ Agricultural University of Athens, Iera Odos 75, 11855 Athens, Greece; aMallouchos@aua.gr \\ * Correspondence: imantzou@agro.duth.gr; Tel./Fax: +30-25520-41137
}

Received: 12 October 2018; Accepted: 12 November 2018; Published: 15 November 2018

\begin{abstract}
A recently isolate from feta type cheese, potential probiotic strain Lactobacillus paracasei $\mathrm{K} 5$, was applied for pomegranate juice (Punica granutum L.) fermentation. Fermentations were carried out for $24 \mathrm{~h}$ followed by the storage of pomegranate juices at $4{ }^{\circ} \mathrm{C}$ for 4 weeks. The parameters examined were a composition of volatile compounds, antioxidant activity, total phenolic content, and consumers' acceptance. The results were encouraging showing that lactic acid fermentation enhanced the composition of volatile compounds even at the fourth week of storage. Increased antioxidant activity (151.44 mg TE/100 mL at the second week) and total phenolics content ( $285 \mathrm{mg}$ GAE/100 mL at the third week) were observed for all the storage times compared to the initial pomegranate beverage. The fermented pomegranate beverage received better scores for the last 3 weeks of cold storage compared to the non-fermented one. Likewise, L. paracasei $\mathrm{K} 5$ was proved to be suitable for the production of functional pomegranate beverages with enhanced aromatic characteristics and high nutritional value.
\end{abstract}

Keywords: potential probiotic; pomegranate beverage; antioxidant activity; phenolics; volatiles

\section{Introduction}

In recent years, increasing consumers' awareness towards the relationship between food and health has led to an explosion of interest regarding functional food products. Functional foods are the ones that have ingredients, aside from the traditional nutrients, which can provide nutritional and physiological benefits to the consumer [1]. Until now, the main category of functional foods are probiotics. As it has been well established, probiotic foods offer various health benefits, mainly providing positive effects on consumers intestinal microbiota [2]. Probiotics are defined as "live microorganisms which when administrated in adequate amounts confer a beneficial effect to the host" [3]. Specifically, in order for probiotic foods to deliver their beneficial properties to the consumer, they should contain a sufficient amount of live probiotic microorganisms $\left(\approx 10^{6}-10^{7} \mathrm{cfu} / \mathrm{g}\right)$ [4]. The main health benefits attributed to live probiotics consumption are the reduction of cholesterol 
levels, immune system stimulation, increased mineral absorption, and antimutagenic, anticarcinogenic, and antihypertensive effects [2].

The use of fruit juices and fruit beverages as vehicles for the delivery of probiotics has increased in the past few years mainly as an alternative for those who do not consume dairy products [3]. The main advantage of fruit juices is that they are perceived as a healthy food consumed by all age groups [5]. In parallel, many target groups, as are lactose intolerance consumers and those who have allergic reactions to dairy products, have increased in numbers the past few years [5].

Fruit juices are considered to be suitable substrates for probiotic bacteria viable cell production, as they already contain many beneficial nutrients including minerals, vitamins, fiber, and antioxidants [3]. As a result, more and more investigation is sought regarding the application of fruit juices as probiotic food carriers, as their main limitation is targeted on the survival of probiotics microorganisms throughout the harsh environmental and storage condition $[5,6]$. Concerning this manner, scientific research has focused on the investigation of various probiotic strains (L. plantarum, L. acidophilus, L. casei, and L. paracasei) which show high tolerance against acidic environments and as a result, can grow and maintain their viability in fruit matrices $[5,7,8]$. After the selection of the appropriate strain, fruit juices are considered to be the most suitable substrates for probiotic bacteria cultivation, as they already contain beneficial nutrients, such as fiber, vitamins, minerals, and antioxidants [5,8].

Among fruit juices, pomegranate seems to be a very good substrate for functional beverage production due to its high nutritional value and anti-oxidative, anti-inflammatory, antimicrobial, and anti-carcinogenic effects $[9,10]$. There are some reports in the literature concerning the fermentation of pomegranate juice with probiotic lactic acid bacteria, showing in general that selected probiotic starters (i) enhanced the health benefits of the juice, (ii) increased the antioxidant activity and total phenolics content, and (iii) led to the production of desirable volatile compounds [7,11-14].

Recently, a novel potential probiotic was isolated from feta type cheese (Lactobacillus paracasei $\mathrm{K} 5)$ and was applied in preliminary fermentations of pomegranate beverage in order the viability to be determined during storage for 4 weeks at $4{ }^{\circ} \mathrm{C}$ [7]. The results were very encouraging since no significant decrease of viability was observed during the storage of the pomegranate beverage at $4{ }^{\circ} \mathrm{C}$ for 4 weeks [7]. Likewise, the main target of this study was to further determine other, also very important technological parameters, such as the composition of volatile compounds, antioxidant activity, and total phenolics content of pomegranate beverages produced after $24 \mathrm{~h}$ of fermentation, as well as during 4 weeks of cold storage. In addition, sensorial tests were conducted.

\section{Results and Discussion}

A novel potential probiotic strain L. paracasei $\mathrm{K} 5$ recently isolated from feta-type cheese was applied in a pomegranate juice fermentation. The main target was the evaluation of microorganism's technological assets during fermentation and 4 weeks of storage of the pomegranate beverage in terms of the evolution of volatile compounds, antioxidant activity, and total phenolics content. In addition, cell viability was retained in levels higher than $7 \log \mathrm{cfu} / \mathrm{mL}$ of juice (data not shown) in all time periods studied, which is in accordance with our previous work [7]. Finally, sensorial tests were conducted after $24 \mathrm{~h}$ of fermentation as well during the 4 weeks of storage.

\subsection{Volatiles Composition and Sensory Evaluation}

The composition of headspace volatile compounds that were identified using HS-SPME/GC-MS in the initial (NFP) and fermented pomegranate (FP) beverage at 0 and $24 \mathrm{~h}$ of fermentation as well as at the first and the last (fourth) week of storage are presented in Table 1. Statistical analysis was employed between the normalized peak area \% of each volatile of NFP and FP for each time period of fermentation or storage. A total of 51 different volatile compounds were identified using HS-SPME/GC-MS. Specifically, the produced pomegranate beverages contained 11 alcohols, 11 aldehydes, 11 ketones, 10 esters, 7 terpenoids, and furfural that varied between samples. The identified volatile compounds 
were verified by the literature as they have also been detected by previous studies in fresh or concentrated pomegranate beverages, pomegranate fruit/seeds, fermented pomegranate beverages through lactic acid fermentation, and other fruits (apples, berries, plums, citrus, exotic fruit, etc.) or fruit beverages $[13,15-23]$.

The groups of volatile compounds that were mainly affected by the fermentation process and storage time were aldehydes, ketones, alcohols, and esters. Specifically, at the first, and more obviously at the fourth week, of pomegranate beverage storage the differences are very significant statistically. At these periods of storage, the volatile composition of NFP decreased significantly regarding the levels of alcohols, ketones, and esters. It is noteworthy that at the first week of storage NFP contained 11 aldehydes in a percentage of $52.5 \%$, while at the fourth week of storage contained 10 aldehydes in a percentage of 59\%. In the contrary, at the same time, FP contained less aldehydes (five aldehydes in a percentage of $6.7 \%$ at the first week, while at the fourth week of storage contained six aldehydes in a percentage of $13 \%$ ). This finding was very interesting since it has been noted that aldehydes cause off flavors and are non-desirable compounds in pomegranate beverages [13,24]. In addition, high proportions of aldehydes in pomegranate beverage are not acceptable from the consumers [25]. Regarding the composition of ketones, NFP contained 10 ketones $(4.8 \%)$ at the first week of storage and $4(1.1 \%)$ at the fourth week of storage, while FP contained 11 ketones $(12.3 \%)$ at the first week of storage and $9(16.4 \%)$ at the fourth week of storage. This outcome is extra evidence of FP distinction over NFP because it has been demonstrated that in general ketones can deliver several positive sensory/aroma attributes [26]. Likewise, fermentation of the pomegranate beverage through Lactobacillus paracasei K5 certainly enhanced the aromatic profile of the pomegranate beverage through the production of desirable volatile compounds. This outcome is in accordance with other investigations proving that lactic acid fermentation enhances the volatile composition of the pomegranate beverage $[13,14]$. Regarding furan products, furfural was identified. Furfural is related with unpleasant coffee-like aromas [27] and was also affected by lactic acid fermentation since it had almost disappeared in the case of FP after the $24 \mathrm{~h}$ of fermentation and during storage, which is in accordance with other investigations [14]. Regarding the composition of esters, NFP contained 3 esters (1.7\%) at the first week of storage and 2 esters $(1.9 \%)$ at the fourth week of storage, while FP contained 10 esters (7.1\%) at the first week of storage and 8 esters $(7.2 \%)$ at the fourth week. This result shows also that lactic acid fermentation positively affected the flavor of the pomegranate beverage because esters play an important role in contributing to fruity notes of fruit juices [28]. Respectable amounts of esters also may be produced by fermentation processes depending on the availability of the alcohol precursors [28]. Finally, respectable amounts of terpenes were found in both NFP and FP (Table 1). Specifically, p-cymene, D-limonene, eucalyptol, linalool, camphor, terinen-4-ol, and $\alpha$-terpineol were identified and their origin is from the pomegranate beverage $[15,19,27]$.

\subsection{Total Phenolics Content (TPC) and Antioxidant Activity (AA)}

NFP and FP was also examined with regard to total phenolics content (TPC). Specifically, initial total phenolics content of freshly prepared pomegranate beverage was about $112 \pm 11 \mathrm{mg} \mathrm{GAE} / 100 \mathrm{~mL}$. In all the time periods, TPC of FP was statistically significantly higher compared to the TPC of NFP (Figure 1). Specifically, TPC of FP reached its highest value at three weeks of storage (285.83 mg GAE eq/100 mL), while TPC of NFP constantly decreased, reaching its lowest value at the fourth week of storage (74.59 mg GAE eq/100 mL). Similar studies have established that Lactic Acid Bacteria (LAB), not always recognized as probiotics, can possess a good antioxidant activity and are be able to positively affect the total phenolics and likewise enhance the TPC of pomegranate beverages $[29,30]$. The main reason is the degradation through enzymes, such as glycosidase, of the complex phenolic compounds of the pomegranate beverage to simpler types that poses high TPC [29]. However, this outcome is very significant since it is the first time it has been recorded that the TPC of fermentation of a lactic acid bacteria pomegranate beverage exhibited very high TPC even at the fourth week of storage. 
Table 1. Volatile compounds identified in the initial pomegranate beverage (NFP) and fermented pomegranate beverage (FP) by Lactobacillus paracasei K5 at $0 \mathrm{~h}$ and 24 $\mathrm{h}$ of fermentation as well at the first week and the fourth week of storage.

\begin{tabular}{|c|c|c|c|c|c|c|c|c|c|}
\hline \multirow{3}{*}{ Compound } & \multirow{3}{*}{$\mathrm{RI}^{1}$} & \multicolumn{7}{|c|}{ Normalized Peak Area \% } & \multirow{3}{*}{ Identification } \\
\hline & & \multirow[t]{2}{*}{$\mathbf{0 h}$} & \multicolumn{2}{|c|}{$24 \mathrm{~h}$} & \multicolumn{2}{|c|}{ First Week } & \multicolumn{2}{|c|}{ Fourth Week } & \\
\hline & & & FP & NFP & FP & NFP & FP & NFP & \\
\hline \multicolumn{10}{|l|}{ Alcohols } \\
\hline Ethyl alcohol & 467 & $0.4 \pm 0.1$ & $15.5 \pm 0.5^{\mathrm{a}}$ & $7.6 \pm 0.3^{b}$ & $32.1 \pm 2.3^{a}$ & $19 \pm 1.8^{\mathrm{b}}$ & $40.4 \pm 1.5^{\mathrm{a}}$ & $23.5 \pm 0.8^{b}$ & MS, RI, ref \\
\hline 1-Butanol & 633 & $3.9 \pm 0.1$ & $5.6 \pm 0.1^{\mathrm{a}}$ & $3.3 \pm 0.2^{b}$ & $11.0 \pm 0.3^{\mathrm{a}}$ & $3.0 \pm 0.1^{b}$ & $3.0 \pm 0.1^{b}$ & $8.5 \pm 0.1^{\mathrm{a}}$ & MS, RI, ref \\
\hline 3-Methyl-1-butanol & 726 & $2.8 \pm 0.4$ & $2.5 \pm 0.3^{a}$ & $<0.1$ & $3.6 \pm 0.5^{\mathrm{a}}$ & nd & $2.4 \pm 0.1^{\mathrm{a}}$ & nd & MS, RI, ref \\
\hline 2-Methyl-1-butanol & 728 & $0.4 \pm 0.1$ & $<0.1$ & $0.6 \pm 0.1^{\mathrm{a}}$ & $2.4 \pm 0.3^{\mathrm{a}}$ & $0.3 \pm 0.1^{b}$ & $0.3 \pm 0.1^{\mathrm{a}, \mathrm{b}}$ & $0.3 \pm 0.1^{\mathrm{a}, \mathrm{b}}$ & MS, RI, ref \\
\hline 3-Methyl-3-buten-1-ol & 724 & $1.2 \pm 0.1$ & $5.3 \pm 0.3^{a}$ & $3.9 \pm 0.4^{b}$ & $3.5 \pm 0.1^{\mathrm{a}}$ & nd & $0.5 \pm 0.1^{\mathrm{a}}$ & nd & MS, RI, ref \\
\hline (E)-3-Hexen-1-ol & 854 & $3.9 \pm 0.1$ & $2.3 \pm 0.1^{\mathrm{a}}$ & nd & $1.3 \pm 0.1^{\mathrm{a}}$ & nd & $2.3 \pm 0.1^{\mathrm{a}}$ & nd & MS, RI, ref \\
\hline (Z)-3-Hexen-1-ol & 864 & $<0.1$ & $0.3 \pm 0.1^{b}$ & $6.5 \pm 0.3^{a}$ & $0.5 \pm 0.1^{\mathrm{a}}$ & nd & $0.4 \pm 0.1^{\mathrm{a}}$ & nd & MS, RI, ref \\
\hline 1-Hexanol & 869 & $15 \pm 1.2$ & $4.8 \pm 0.2^{\mathrm{a}}$ & nd & $6.5 \pm 0.4^{\mathrm{a}}$ & nd & $6.6 \pm 0.3^{a}$ & nd & MS, RI, ref \\
\hline 2-Heptanol & 903 & $0.4 \pm 0.1$ & $<0.1$ & $0.5 \pm 0.1^{a}$ & $0.5 \pm 0.1^{\mathrm{a}}$ & nd & nd & nd & MS, RI, ref \\
\hline 2-Ethyl-1-hexanol & 1032 & $0.6 \pm 0.2$ & $0.8 \pm 0.1^{\mathrm{a}}$ & nd & $0.5 \pm 0.1^{\mathrm{a}}$ & nd & $1.3 \pm 0.1^{\mathrm{a}}$ & nd & MS, RI, ref \\
\hline 1-Nonanol & 1177 & $1.9 \pm 0.2$ & $0.3 \pm 0.1^{\mathrm{a}}$ & nd & $3.0 \pm 0.1^{\mathrm{a}}$ & nd & nd & nd & MS, RI, ref \\
\hline \multicolumn{10}{|l|}{ Aldehydes } \\
\hline Acetaldehyde & 459 & $<0.1$ & $0.7 \pm 0.1^{\mathrm{a}}$ & $0.3 \pm 0.1^{b}$ & nd & $<0.1$ & $<0.1$ & nd & MS, RI \\
\hline 3-Methyl-butanal & 615 & $0.9 \pm 0.2$ & $0.7 \pm 0.1^{b}$ & $3.5 \pm 0.3^{a}$ & $0.3 \pm 0.1^{\mathrm{b}}$ & $2.9 \pm 0.1^{a}$ & $0.4 \pm 0.1^{\mathrm{b}}$ & $4.6 \pm 0.3^{a}$ & MS, RI \\
\hline 2-Methyl-butanal & 630 & $0.3 \pm 0.1$ & $0.3 \pm 0.1^{b}$ & $2.1 \pm 0.1^{\mathrm{a}}$ & $0.3 \pm 0.1^{b}$ & $3.2 \pm 0.1^{\mathrm{a}}$ & $<0.1$ & $5.1 \pm 0.4^{\mathrm{a}}$ & MS, RI \\
\hline Hexanal & 795 & $1.1 \pm 0.2$ & $0.8 \pm 0.1^{\mathrm{a}}$ & $0.3 \pm 0.1^{b}$ & $0.3 \pm 0.1^{b}$ & $1.2 \pm 0.1^{\mathrm{a}}$ & $0.7 \pm 0.1^{\mathrm{b}}$ & $3.1 \pm 0.1^{\mathrm{a}}$ & MS, RI, ref \\
\hline Heptanal & 903 & $<0.1$ & $<0.1$ & $7.5 \pm 08$ & nd & $12.5 \pm 0.1^{\mathrm{a}}$ & nd & $12.5 \pm 0.1^{\mathrm{a}}$ & MS, RI \\
\hline Benzaldehyde & 957 & $<0.1$ & $<0.1$ & $14 \pm 1.1^{\mathrm{a}}$ & nd & $2.1 \pm 0.1^{\mathrm{a}}$ & nd & $0.6 \pm 0.1^{\mathrm{a}}$ & MS, RI, ref \\
\hline Octanal & 1004 & $<0.1$ & $<0.1$ & $2.7 \pm 0.4^{\mathrm{a}}$ & nd & $12.5 \pm 0.1^{\mathrm{a}}$ & nd & $9.9 \pm 0.8^{\mathrm{a}}$ & MS, RI, ref \\
\hline Benzeneacetaldehyde & 1042 & $<0.1$ & $1.5 \pm 0.1^{b}$ & $12.4 \pm 0.8^{a}$ & $0.8 \pm 0.1^{b}$ & $13.9 \pm 0.1^{\mathrm{a}}$ & $1.2 \pm 0.2^{\mathrm{a}}$ & $13.1 \pm 0.3^{a}$ & MS, RI \\
\hline Nonanal & 1105 & $0.6 \pm 0.1$ & $11.4 \pm 0.1^{\mathrm{a}}$ & $8.2 \pm 0.4^{b}$ & $5.0 \pm 0.1^{b}$ & $8.8 \pm 0.1^{\mathrm{a}}$ & $10.7 \pm 0.1^{b}$ & $8.0 \pm 0.4^{\mathrm{a}}$ & MS, RI \\
\hline Undecanal & 1310 & $<0.1$ & $<0.1$ & $2.4 \pm 0.4^{\mathrm{a}}$ & nd & $2.1 \pm 0.1^{\mathrm{a}}$ & nd & $2.1 \pm 0.3^{\mathrm{a}}$ & MS, RI \\
\hline Dodecanal & 1412 & $<0.1$ & $<0.1$ & $4.8 \pm 0.3^{a}$ & nd & $1.6 \pm 0.1^{a}$ & nd & $2.1 \pm 0.2^{\mathrm{a}}$ & MS, RI \\
\hline \multicolumn{10}{|l|}{ Ketones } \\
\hline 2,3-Butanedione & 533 & $0.4 \pm 0.1$ & $<0.1$ & $0.3 \pm 0.1^{\mathrm{a}}$ & $1.2 \pm 0.2^{\mathrm{a}}$ & $<0.1$ & $<0.1$ & nd & MS, RI, ref \\
\hline 2-Butanone & 542 & $2.2 \pm 0.5$ & $0.6 \pm 0.1^{b}$ & $1.5 \pm 0.2^{\mathrm{a}}$ & $0.5 \pm 0.1^{a, b}$ & $0.5 \pm 0.1^{\mathrm{a}, \mathrm{b}}$ & $0.5 \pm 0.1^{\mathrm{a}}$ & nd & MS, RI \\
\hline 2-Pentanone & 678 & $2.9 \pm 0.3$ & $1.2 \pm 0.2^{\mathrm{a}}$ & $0.5 \pm 0.1^{b}$ & $0.7 \pm 0.1^{\mathrm{a}}$ & $0.2 \pm 0.1^{b}$ & $0.9 \pm 0.1^{\mathrm{a}}$ & nd & MS, RI \\
\hline 3-Pentanone & 700 & $2.5 \pm 0.1$ & $3.8 \pm 0.1^{\mathrm{a}}$ & $<0.1$ & $3.2 \pm 0.1^{\mathrm{a}}$ & $0.7 \pm 0.1^{b}$ & $3.7 \pm 0.1^{\mathrm{a}}$ & nd & MS, RI \\
\hline 3-Hexanone & 777 & $1.1 \pm 0.2$ & $0.9 \pm 0.1^{\mathrm{a}}$ & $0.4 \pm 0.1^{b}$ & $0.8 \pm 0.1^{\mathrm{a}}$ & $0.7 \pm 0.1^{b}$ & $0.5 \pm 0.1^{\mathrm{a}}$ & nd & MS, RI \\
\hline
\end{tabular}


Table 1. Cont

\begin{tabular}{|c|c|c|c|c|c|c|c|c|c|}
\hline \multirow{3}{*}{ Compound } & \multirow{3}{*}{$\mathrm{RI}^{1}$} & \multicolumn{7}{|c|}{ Normalized Peak Area \% } & \multirow{3}{*}{ Identification $^{2}$} \\
\hline & & \multirow[t]{2}{*}{$\mathbf{0 h}$} & \multicolumn{2}{|c|}{$24 \mathrm{~h}$} & \multicolumn{2}{|c|}{ First Week } & \multicolumn{2}{|c|}{ Fourth Week } & \\
\hline & & & FP & NFP & FP & NFP & FP & NFP & \\
\hline 2-Hexanone & 784 & $1.1 \pm 0.1$ & $1.7 \pm 0.1^{\mathrm{a}, \mathrm{b}}$ & $1.6 \pm 0.1^{\mathrm{a}, \mathrm{b}}$ & $1.6 \pm 0.1^{\mathrm{a}, \mathrm{b}}$ & $1.6 \pm 0.1^{\mathrm{a}, \mathrm{b}}$ & $1.4 \pm 0.1^{\mathrm{a}}$ & nd & MS, RI \\
\hline 2-Heptanone & 893 & $0.4 \pm 0.1$ & $0.4 \pm 0.1^{\mathrm{a}, \mathrm{b}}$ & $0.4 \pm 0.1^{\mathrm{a}, \mathrm{b}}$ & $0.3 \pm 0.1^{\mathrm{a}}$ & $<0.1$ & $0.6 \pm 0.1^{\mathrm{a}}$ & $<0.1$ & MS, RI \\
\hline 3-Heptanone & 887 & $0.3 \pm 0.1$ & $0.3 \pm 0.1^{\mathrm{b}}$ & $0.6 \pm 0.1^{\mathrm{a}}$ & $0.3 \pm 0.1^{\mathrm{a}}$ & $<0.1$ & $0.4 \pm 0.1^{\mathrm{a}}$ & $<0.1$ & MS, RI \\
\hline 4-Methyl-2-heptanone & 939 & $14.5 \pm 1.4$ & $13.1 \pm 0.3^{\mathrm{a}}$ & $0.9 \pm 0.1^{\mathrm{a}}$ & $2.5 \pm 0.1^{\mathrm{a}}$ & nd & $8.4 \pm 0.4^{\mathrm{a}}$ & nd & MS, RI \\
\hline 6-Methyl-5-hepten-2-one & 990 & $0.4 \pm 0.1$ & $0.4 \pm 0.1^{\mathrm{b}}$ & $0.8 \pm 0.1^{\mathrm{a}}$ & $0.5 \pm 0.1^{\mathrm{a}, \mathrm{b}}$ & $0.5 \pm 0.1^{\mathrm{a}, \mathrm{b}}$ & nd & $0.5 \pm 0.1^{\mathrm{a}}$ & MS, RI \\
\hline 2-Nonanone & 1094 & $<0.1$ & $0.7 \pm 0.1^{\mathrm{b}}$ & $1.6 \pm 0.1^{\mathrm{a}}$ & $0.3 \pm 0.1^{b}$ & $0.6 \pm 0.1^{\mathrm{a}}$ & nd & $0.6 \pm 0.1^{\mathrm{a}}$ & MS, RI \\
\hline \multicolumn{10}{|l|}{ Esters } \\
\hline Methyl acetate & 494 & $1.5 \pm 0.2$ & $0.3 \pm 0.1^{\mathrm{a}, \mathrm{b}}$ & $0.3 \pm 0.1^{\mathrm{a}, \mathrm{b}}$ & $0.8 \pm 0.1^{\mathrm{a}}$ & $0.3 \pm 0.1^{b}$ & $0.3 \pm 0.1^{\mathrm{a}, \mathrm{b}}$ & $0.3 \pm 0.1^{\mathrm{a}, \mathrm{b}}$ & MS, RI, ref \\
\hline Ethyl acetate & 560 & $2.7 \pm 0.4$ & $2.8 \pm 0.1^{\mathrm{a}}$ & $2.8 \pm 0.1^{b}$ & $1.2 \pm 0.1^{\mathrm{a}}$ & $1.4 \pm 0.1^{b}$ & $1.5 \pm 0.1^{\mathrm{a}}$ & $1.6 \pm 0.1^{b}$ & MS, RI, ref \\
\hline$n$-Propyl acetate & 711 & $0.6 \pm 0.1$ & $0.9 \pm 0.1^{\mathrm{a}}$ & nd & $<0.1$ & nd & $0.9 \pm 0.1^{\mathrm{a}}$ & nd & MS, RI, ref \\
\hline Ethyl propanoate & 709 & $<0.1$ & $1.0 \pm 0.1^{\mathrm{a}}$ & $<0.1$ & $1.0 \pm 0.1^{\mathrm{a}}$ & nd & $0.5 \pm 0.1^{\mathrm{a}}$ & nd & MS, RI, ref \\
\hline Isobutyl acetate & 765 & $1.2 \pm 0.3$ & $1.3 \pm 0.1^{\mathrm{a}}$ & $0.7 \pm 0.1^{b}$ & $0.5 \pm 0.1^{\mathrm{a}}$ & nd & $1.2 \pm 0.1^{\mathrm{a}}$ & nd & MS, RI, ref \\
\hline 2-Methyl-2-butyl acetate & 805 & $1.6 \pm 0.3$ & $1.5 \pm 0.1^{\mathrm{a}}$ & $0.4 \pm 0.1^{b}$ & $1.8 \pm 0.1^{\mathrm{a}}$ & nd & $1.3 \pm 0.1^{\mathrm{a}}$ & nd & MS, RI, ref \\
\hline 3-Methyl-1-butyl acetate & 877 & $1.1 \pm 0.2$ & $1.5 \pm 0.1^{b}$ & $0.9 \pm 0.1^{\mathrm{a}}$ & $0.7 \pm 0.1^{\mathrm{a}}$ & $<0.1$ & nd & nd & MS, RI, ref \\
\hline Methyl benzoate & 1093 & $1.0 \pm 0.2$ & $1.4 \pm 0.1^{\mathrm{a}}$ & nd & $0.9 \pm 0.1^{\mathrm{a}}$ & nd & $1.1 \pm 0.2^{\mathrm{a}}$ & nd & MS, RI \\
\hline Ethyl octanoate & 1201 & $<0.1$ & $1.0 \pm 0.1^{\mathrm{a}}$ & nd & $0.6 \pm 0.1^{\mathrm{a}}$ & nd & nd & nd & MS, RI \\
\hline Ethyl decanoate & 1400 & $0.4 \pm 0.1$ & $0.7 \pm 0.1^{\mathrm{a}}$ & nd & $0.5 \pm 0.1^{\mathrm{a}}$ & nd & $0.3 \pm 0.1^{\mathrm{a}}$ & nd & MS, RI \\
\hline \multicolumn{10}{|l|}{ Terpenoids } \\
\hline p-Cymene & 1021 & $1.4 \pm 0.1$ & $2.4 \pm 0.3^{\mathrm{a}}$ & $<0.1$ & $2.8 \pm 0.1^{\mathrm{a}}$ & $0.5 \pm 0.1^{b}$ & $1.0 \pm 0.1^{\mathrm{a}}$ & $0.5 \pm 0.1^{b}$ & MS, RI, ref \\
\hline D-Limonene & 1025 & $0.4 \pm 0.1$ & $3.8 \pm 0.7^{\mathrm{a}}$ & $0.3 \pm 0.1^{b}$ & $1.2 \pm 0.1^{\mathrm{a}}$ & $0.3 \pm 0.1^{b}$ & $1.8 \pm 0.1^{\mathrm{a}}$ & $0.9 \pm 0.1^{b}$ & MS, RI, ref \\
\hline Eucalyptol & 1027 & $0.4 \pm 0.1$ & $0.8 \pm 0.1^{\mathrm{a}}$ & $<0.1$ & $0.8 \pm 0.1^{\mathrm{a}}$ & $0.3 \pm 0.1^{b}$ & $2.0 \pm 0.3^{a}$ & $0.4 \pm 0.1^{b}$ & MS, RI, ref \\
\hline Linalool & 1100 & $0.3 \pm 0.1$ & $1.2 \pm 0.2^{\mathrm{a}}$ & $0.4 \pm 0.1^{\mathrm{b}}$ & $0.4 \pm 0.1^{\mathrm{a}}$ & $<0.1$ & nd & $<0.1$ & MS, RI, ref \\
\hline Camphor & 1139 & $0.6 \pm 0.1$ & $0.8 \pm 0.1^{\mathrm{a}, \mathrm{b}}$ & $0.8 \pm 0.1^{\mathrm{a}, \mathrm{b}}$ & $0.7 \pm 0.1^{\mathrm{a}}$ & nd & $0.6 \pm 0.1^{\mathrm{a}}$ & nd & MS, RI, ref \\
\hline Terpinen-4-ol & 1174 & $0.3 \pm 0.1$ & $1.2 \pm 0.1^{\mathrm{a}}$ & $0.7 \pm 0.1^{\mathrm{b}}$ & $0.9 \pm 0.1^{\mathrm{a}}$ & $0.4 \pm 0.1^{b}$ & nd & $0.5 \pm 0.1^{\mathrm{a}}$ & MS, RI, ref \\
\hline a-Terpineol & 1189 & $1.0 \pm 0.1$ & $1.2 \pm 0.1^{\mathrm{a}}$ & $0.6 \pm 0.1^{b}$ & $0.8 \pm 0.1^{\mathrm{a}}$ & nd & $0.7 \pm 0.1^{\mathrm{a}}$ & nd & MS, RI \\
\hline \multicolumn{10}{|l|}{ Others } \\
\hline Furfural & 705 & $14.10 \pm 0.1$ & $0.8 \pm 0.1^{b}$ & $2.9 \pm 0.1^{\mathrm{a}}$ & $0.7 \pm 0.1^{b}$ & $8.9 \pm 0.1^{\mathrm{a}}$ & $<0.1$ & $1.3 \pm 0.1^{b}$ & MS, RI, ref \\
\hline
\end{tabular}

1 Experimental retention indices on MEGA-5 HT column. ${ }^{2}$ Identification confirmed by MS, mass spectra; RI, retention indices provided with NIST14 and FFNSC mass spectral library; ref, identified by comparison to authentic compound. Unless confirmed by comparison to authentic standards, compounds are considered as tentatively identified. Different superscript letters in a row at the same time period for NFP and FP indicates statistically significant differences (ANOVA, Duncan's multiple range test, $p<0.05$ ). nd: not identified. 


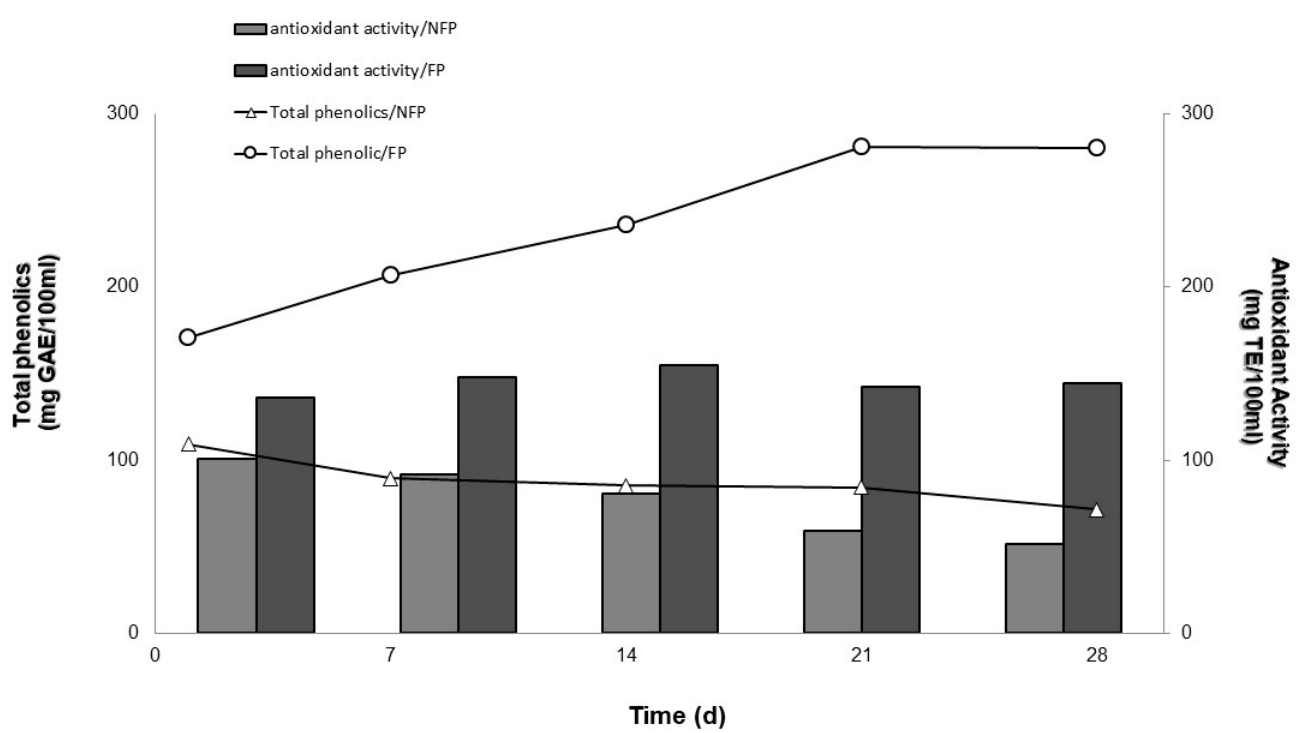

Figure 1. Total phenolics content $(\mathrm{mg} \mathrm{GAE} / 100 \mathrm{~mL})$ and antioxidant activity $(\mathrm{mg}$ TE/100 mL) of non-fermented (NFP) and fermented with Lactobacillus paracasei $\mathrm{K} 5$ (FP) pomegranate beverages during the first $24 \mathrm{~h}\left(30^{\circ} \mathrm{C}\right)$ and during refrigerated storage $\left(4{ }^{\circ} \mathrm{C}\right)$ for 4 weeks.

Regarding the antioxidant activity (AA) of fermented pomegranate beverage, the results are presented in Figure 1. Initial AA of the freshly prepared pomegranate beverage was about $121 \pm 10 \mathrm{mg}$ $\mathrm{TE} / 100 \mathrm{~mL}$. In all the time periods, AA of FP was statistically significantly higher compared to the AA of NFP (Figure 1). Likewise, AA seemed to have a similar asset as TPC. This is in accordance with a late investigation claiming that the AA increased together with the phenolic derivatives concentrations, mainly in the juices fermented with Lactobacillus [11]. These derivatives were formed due to the LAB metabolism of the ellagitannins, epicatechin, and catechin after fermentation [11].

The highest value for AA of FP was observed at the first week of storage (151.44 mg TE/100 mL), while the AA of NFP constantly decreased, reaching its lowest value at the fourth week of storage (51.20 mg TE/100 mL). It seems that lactic acid fermentation also enhanced the AA of the pomegranate beverage as other researchers have also found. Specifically, similar findings were observed by other studies in pomegranate beverages fermented using probiotic lactic acid bacteria [14,30].

\subsection{Sensory Evaluation}

The preliminary sensory evaluation was performed by non-trained testers (consumers) to evaluate the produced NFP and FP in terms of the juices' fruity, sour, astringent, bitter, alcoholic, sweet, and fresh qualities, and overall acceptability in comparison with commercial pomegranate juice. In general, all pomegranate beverages were accepted by the consumers as illustrated in Figure 2. It is noteworthy that the commercial pomegranate juice received higher scores for sourness, bitterness, and astringency compared to NFP and FP. Pomegranate juice is usually characterized by an astringent mouthfeel as well as earthy notes, which can lead to a sour and bitter essence [31]. As a result, these attributes can hinder consumer acceptance. On the other hand, both non-fermented (NFP) and fermented (FP) pomegranate beverages were characterized as sweeter with a slight alcoholic sense while FP retrieved the lowest scores for bitterness, sourness, and astringency. In addition, panelists scored the FP significantly better compared to NFP regarding overall acceptance. These results are in accordance with previous studies that had correlated the volatile compound composition of fermented and non-fermented pomegranate juices and found that the fermented juice provided an enhanced volatile composition and received higher evaluation scores compared to non-fermented juices [13]. As a result, it is highlighted that lactic acid fermentation promotes flavour attributes in fermented pomegranate beverages. 


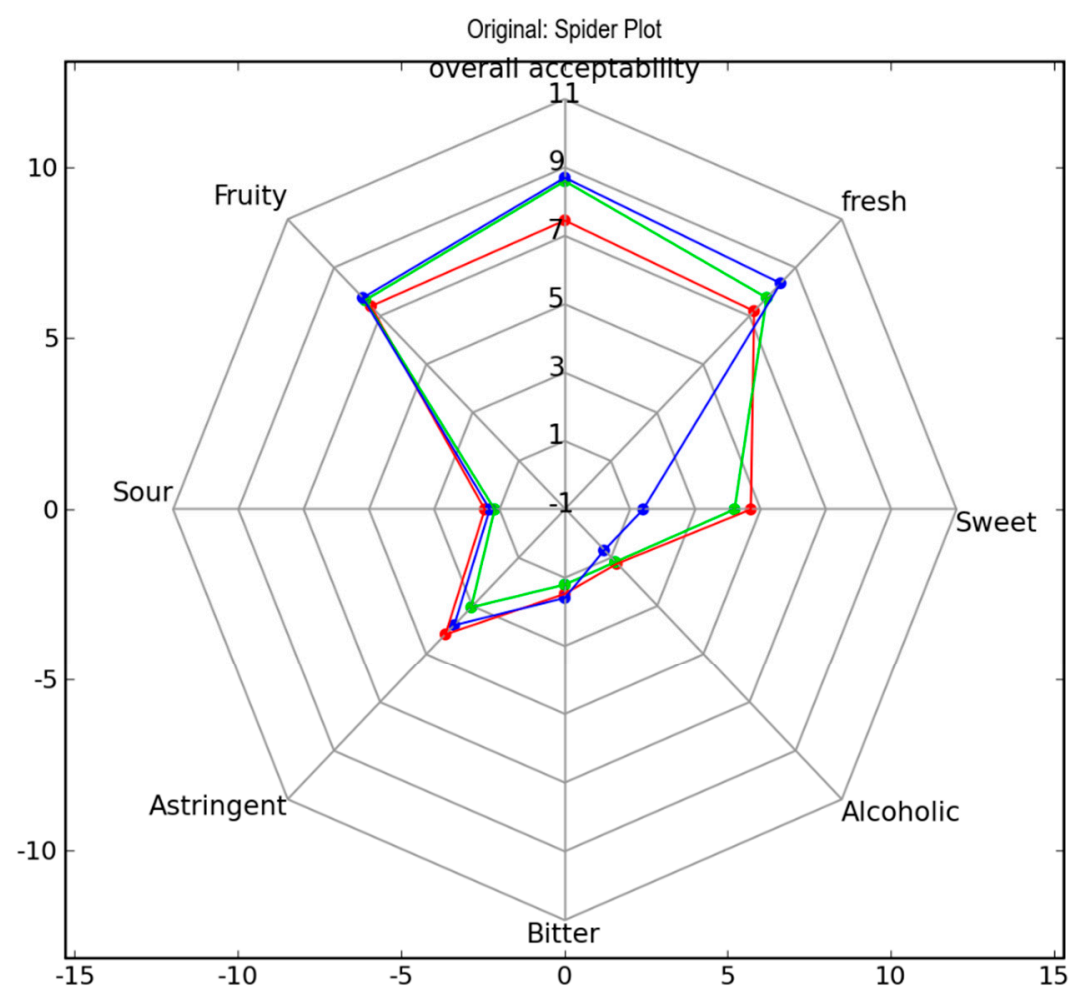

Figure 2. Star chart of the sensory attributes (fruity, sour, astringent, bitter, alcoholic, sweet, fresh, and overall acceptability) evaluated in pomegranate beverages during refrigeration.

\section{Materials and Methods}

\subsection{Microbial Starter Culture Preparation}

The novel potential probiotic strain Lactobacillus paracasei $\mathrm{K} 5$, isolated from Greek feta-type cheese [7], kept at the Democritus University of Thrace was grown under anaerobic conditions at $37^{\circ} \mathrm{C}$ for 24-48 $\mathrm{h}$ in Man, Rogosa and Sharpe (MRS) broth. Wet biomass was harvested using centrifugation (Sigma 3K12, Bioblock Scientific, Illkirch, France) at $5000 \mathrm{rpm}$ for $10 \mathrm{~min}$ at $25^{\circ} \mathrm{C}$. All media were autoclaved at $120^{\circ} \mathrm{C}$ and at $1-1.5 \mathrm{~atm}$ for $15 \mathrm{~min}$ prior to use.

\subsection{Pomegranate Beverage Production}

Fresh pomegranates (Punica granatum L.) were obtained via a local market (Orestiada, Greece). Fresh fruits were carefully selected, peeled, and processed into juice by blending the seeds for $10 \mathrm{~min}$ in a mixer. The adjustment of the initial sugar concentration was conducted to approximately $90 \mathrm{~g} / \mathrm{L}$ by dilution with sterilized and deionized water [7]. Then the pomegranate diluted juice with the incorporated sugar was pasteurized for $5 \mathrm{~min}$ at $80^{\circ} \mathrm{C}$. The pasteurized mixture was cooled at room temperature $\left(\approx 18-20^{\circ} \mathrm{C}\right)$ [32]. Lactobacillus paracasei $\mathrm{K} 5$ wet culture $(2 \mathrm{~g})$ was added in $100 \mathrm{~mL}$ of fermentation substrate. The initial $\mathrm{pH}$ of the substrates was adjusted to 3.5. The substrates were fermented at $30{ }^{\circ} \mathrm{C}$ for $24 \mathrm{~h}$ and then the flasks were kept at $4{ }^{\circ} \mathrm{C}$ for 28 days (4 weeks). The fermentations were carried out in triplicate.

\subsection{Headspace Solid Phase Micro Extraction-Gas Chromatography/Mass Volatiles Analysis Using HS-SPME/GC-MS}

The volatile compounds of produced pomegranate beverages were determined by HS-SPME/GC-MS method, as described previously by Vázquez-Araújo with small modifications [27]. Each sample $(2 \mathrm{~mL})$ was pipetted into $4 \mathrm{~mL}$ glass container and sealed with a screw-cap with polytetrafluoroethylene (PTFE)-lined silicone septum. The vials were placed in a water-bath at $40{ }^{\circ} \mathrm{C}$ 
and magnetically stirred for $5 \mathrm{~min}$ at $250 \mathrm{rpm}$ before exposing the fiber (DVB/CAR/PDMS, needle size 24 ga, length $1 \mathrm{~cm}$, Sigma Aldrich, Darmstadt, Germany) for $30 \mathrm{~min}$ at the same conditions.

Desorption of volatiles was effected at $250^{\circ} \mathrm{C}$ for $2 \mathrm{~min}$ (splitless) in the inlet of GC-MS system (Shimadzu QP-2010 Ultra, Kyoto, Japan) The fiber was then left in the inlet (split ratio 1/50) for another $8 \mathrm{~min}$ to prevent carryover effects. Compounds were separated on a MEGA-5 HT column (30 $\mathrm{m} \times 0.25 \mathrm{~mm}$ i.d., film thickness $0.25 \mu \mathrm{m}$, Mega s.n.c., Milan, Italy) using helium as a carrier gas at a constant linear velocity $(35 \mathrm{~cm} / \mathrm{s})$. During analysis, the oven was kept at $40{ }^{\circ} \mathrm{C}$ for $5 \mathrm{~min}$, then increased at $4{ }^{\circ} \mathrm{C} / \mathrm{min}$ up to $150{ }^{\circ} \mathrm{C}$, followed by $30^{\circ} \mathrm{C} / \mathrm{min}$ up to $260{ }^{\circ} \mathrm{C}$, and held for $5 \mathrm{~min}$. The mass spectrometer was operated in the electron ionization mode with the electron energy set at $70 \mathrm{eV}$ and scan mass range of $40-400 \mathrm{~m} / \mathrm{z}$. Source and interface temperatures were set at 200 and $270{ }^{\circ} \mathrm{C}$, respectively.

The compounds were identified by comparing the linear retention indices based on the homologous series of n-alkanes (C7-C24) with those of reference compounds and those of NIST14 and FFNSC MS library (Chromaleont S.r.l., Milan, Italy) and MS data with those of reference compounds and by MS data obtained from NIST14 and FFNSC libraries. GCMS solution (Shimadzu) and Amdis (NIST) software (Kyoto, Japan) were used in the identification process. The relative amounts of individual components were calculated on the basis of peak area (from Amdis) without using any correction factor.

\subsection{Total Phenolics and Antioxidant Activity}

Total phenolics content (TPC) was determined by using the Folin-Ciocalteu reagent based on colorimetric reduction [33]. The phenolics compounds were oxidized to phenolates using the reagent at alkaline $\mathrm{pH}$ in a saturated solution of sodium carbonate resulting in a blue complex. About $1 \mathrm{~mL}$ of Folin-Ciocalteau $(10 \%, w / v)$ was added to $0.2 \mathrm{~mL}$ of prepared pomegranate beverage, followed by the addition of $1.2 \mathrm{~mL}$ of aqueous $\mathrm{Na}_{2} \mathrm{CO}_{3}(7.5 \%, w / v)$. The mixture was left in the dark for $90 \mathrm{~min}$. The absorbance of the blue color solution was monitored at $760 \mathrm{~nm}$ on a UV visible spectrophotometer (Shimadzu, Kyoto, Japan), against blank (distilled water). The Total Phenolics Content (TPC) was assessed by plotting the gallic acid calibration curve and expressed as milligrams of gallic acid equivalents per liter of sample.

Total phenolics concentration $(\mathrm{mg} / \mathrm{mL})$ of the samples were analyzed in triplicates and extrapolated from a standard curve constructed by using Gallic acid as a standard. Results were expressed as $\mathrm{mg}$ Gallic acid equivalents (GAE)/100 $\mathrm{mL}$ of pomegranate beverage.

The antioxidant activity (AA) of pomegranate beverages was evaluated applying the 2,2'-Azino-bis(3-ethylbenzothiazoline-6-sulfonic acid) diammonium salt (ABTS) radical cation decolorization assay [34]. ABTS $\bullet+$ was prepared by reacting of ABTS with potassium persulfate. Samples were analyzed at five different dilutions, within the linearity range of the assay, as previous described [35]. TAA was expressed as $\mathrm{mg}$ Trolox equivalent (TE)/100 $\mathrm{mL}$ of pomegranate beverage. All measurements were repeated three times.

\subsection{Sensory Evaluation}

A group of 20 panellists (aged between 25 and 65 years) who were frequent consumers of pomegranates (five to seven times of consumption per month during the pomegranate season) participated in taste panels. Sensory evaluation of pomegranate beverages was carried out in panel booths conforming to international standards (International standard, 2007). Produced pomegranate beverages (FP, NFP) were compared with commercial pomegranate juice $(\mathrm{P})$. The samples were coded by a different three-digit number and served in a randomized order. The evaluators were asked to taste the samples and score the intensity of the following attributes: fruity, sour, astringent, bitter, alcoholic, sweet, fresh, and overall acceptability [31]. The intensity of the studied attributes was conducted on a $0-10 \mathrm{~cm}$ unstructured linear scale (the higher the number the greater the intensity) anchored with 
the words "high intensity" and "absence" on the right and left ends, respectively [36]. The results are presented as a star chart of the product's attributes.

\subsection{Statistical Analysis}

The data obtained from the aroma volatile compounds, antioxidant activity, total phenolics content, and sensorial analysis of the initial pomegranate beverage and fermented pomegranate beverage were analyzed for their mean differences with the analysis of variance (ANOVA) procedure followed by Duncan's post hoc multiple range test to extract the specific differences between the various treatments. Analysis was performed by using an IMB SPSS v20 (IBM Corp, International Business Machines) at an $\alpha$ level of $5 \%$.

\section{Conclusions}

The obtained results showed that the fermentation of pomegranate beverage with the novel Lactobacillus paracasei $\mathrm{K} 5$ led to an enriched composition of volatile compounds, higher antioxidant activity, and higher total phenolics contents compared to the initial pomegranate beverage for all the time periods examined. In addition, the fermented pomegranate beverage was scored better by consumers compared to the non-fermented juice. Finally, L. paracasei K5 was proved to be suitable for the production of potential probiotic pomegranate beverages of a high nutritional value.

Author Contributions: I.M., S.K. and A.T. performed most of the experiments with support from S.P., S.P. conceived the project, S.P. and I.M. designed the experiments, I.M., A.A., A.M., A.K. and E.B. analyzed the data and I.M. wrote the manuscript.

Funding: This research received no external funding.

Conflicts of Interest: The authors declare no conflict of interest

\section{References}

1. Ye, Q.; Georges, N.; Selomulya, C. Microencapsulation of active ingredients in functional foods: From research stage to commercial food products. Trends Food Sci. Technol. 2018, 78, 167-179. [CrossRef]

2. George Kerry, R.; Patra, J.K.; Gouda, S.; Park, Y.; Shin, H.-S.; Das, G. Benefaction of probiotics for human health: A review. J. Food Drug Anal. 2018, 26, 927-939. [CrossRef] [PubMed]

3. Fernandes Pereira, A.L.; Rodrigues, S. Chapter 15-Turning Fruit Juice Into Probiotic Beverages. In Fruit Juices; Rajauria, G., Tiwari, B.K., Eds.; Academic Press: San Diego, CA, USA, 2018; pp. 279-287.

4. Plessas, S.; Bosnea, L.; Alexopoulos, A.; Bezirtzoglou, E. Potential effects of probiotics in cheese and yogurt production: A review. Eng. Life Sci. 2012, 12, 433-440. [CrossRef]

5. Perricone, M.; Bevilacqua, A.; Altieri, C.; Sinigaglia, M.; Corbo, R.M. Challenges for the Production of Probiotic Fruit Juices. Beverages 2015, 1, 95-103. [CrossRef]

6. Lebaka, V.R.; Wee, Y.J.; Narala, V.R.; Joshi, V.K. Chapter 4-Development of New Probiotic Foods-A Case Study on Probiotic Juices. In Therapeutic, Probiotic, and Unconventional Foods; Grumezescu, A.M., Holban, A.M., Eds.; Academic Press: San Diego, CA, USA, 2018; pp. 55-78.

7. Plessas, S.; Nouska, C.; Karapetsas, A.; Kazakos, S.; Alexopoulos, A.; Mantzourani, I.; Chondrou, P.; Fournomiti, M.; Galanis, A.; Bezirtzoglou, E. Isolation, characterization and evaluation of the probiotic potential of a novel Lactobacillus strain isolated from Feta-type cheese. Food Chem. 2017, 226, 102-108. [CrossRef] [PubMed]

8. Nualkaekul, S.; Charalampopoulos, D. Survival of Lactobacillus plantarum in model solutions and fruit juices. Int. J. Food Microbiol. 2011, 146, 111-117. [CrossRef] [PubMed]

9. Karimi, M.; Sadeghi, R.; Kokini, J. Pomegranate as a promising opportunity in medicine and nanotechnology. Trends Food Sci. Technol. 2017, 69, 59-73. [CrossRef]

10. Singh, B.; Singh, J.P.; Kaur, A.; Singh, N. Phenolic compounds as beneficial phytochemicals in pomegranate (Punica granatum L.) peel: A review. Food Chem. 2018, 261, 75-86. [CrossRef] [PubMed] 
11. Valero-Cases, E.; Nuncio-Jáuregui, N.; Frutos, M.J. Influence of Fermentation with Different Lactic Acid Bacteria and in Vitro Digestion on the Biotransformation of Phenolic Compounds in Fermented Pomegranate Juices. J. Agric. Food Chem. 2017, 65, 6488-6496. [CrossRef] [PubMed]

12. Murthy, S.N.; Patnaik, A.; Srinivasan, N.; Selvarajan, E.; Nivetha, A.; Mohanasrinivasan, V. Fermentative preparation of functional drink from Punica granatum using lactic acid bacteria and exploring its anti-tumor potential. Mater. Sci. Eng. 2017, 263, 022045. [CrossRef]

13. Di Cagno, R.; Filannino, P.; Gobbetti, M. Lactic acid fermentation drives the optimal volatile flavor-aroma profile of pomegranate juice. Int. J. Food Microbiol. 2017, 248, 56-62. [CrossRef] [PubMed]

14. Filannino, P.; Azzi, L.; Cavoski, I.; Vincentini, O.; Rizzello, C.G.; Gobbetti, M.; Di Cagno, R. Exploitation of the health-promoting and sensory properties of organic pomegranate (Punica granatum L.) juice through lactic acid fermentation. Int. J. Food Microbiol. 2013, 163, 184-192. [CrossRef] [PubMed]

15. Beaulieu, J.C.; Obando-Ulloa, J.M. Not-from-concentrate pilot plant 'Wonderful' cultivar pomegranate juice changes: Volatiles. Food Chem. 2017, 229, 553-564. [CrossRef] [PubMed]

16. Allam, M.G.M.; Darwish, A.M.G.; Ayad, E.H.E.; Shokery, E.S.; Mashaly, R.E.; Darwish, S.M. In vivo evaluation of safety and probiotic traits of isolated Enterococcus feacium strain KT712. Res. J. Microbiol. 2016, 11, 169-177. [CrossRef]

17. Beaulieu, J.C.; Stein-Chisholm, R.E. HS-GC-MS volatile compounds recovered in freshly pressed 'Wonderful' cultivar and commercial pomegranate juices. Food Chem. 2016, 190, 643-656. [CrossRef] [PubMed]

18. Jung, J.S. Analysis of volatile compounds in the root peel, stem peel, and fruit peel of pomegranate (Punica granatum) by TD GC/MS. J. Biosci. Biotechnol. 2014, 6, 169-181. [CrossRef]

19. Andreu-Sevilla, A.J.; Mena, P.; Martí, N.; García Viguera, C.; Carbonell-Barrachina, Á.A. Volatile composition and descriptive sensory analysis of pomegranate juice and wine. Food Res. Int. 2013, 54, 246-254. [CrossRef]

20. Bicas, J.L.; Molina, G.; Dionísio, A.P.; Barros, F.F.C.; Wagner, R.; Maróstica, M.R., Jr.; Pastore, G.M. Volatile constituents of exotic fruits from Brazil. Food Res. Int. 2011, 44, 1843-1855. [CrossRef]

21. De Souza Sant'Ana, A. Special Issue on Exotic Fruits. Food Res. Int. 2011, 44, 1657. [CrossRef]

22. Guiné, R.P.; Martín-Belloso, O.; Mínguez-Mosquera, M.I.; Paliyath, G.; Pessoa, F.L.; Le Quéré, J.L.; Sidhu, J.S.; Sinha, N.; Stanfield, P. Handbook of Fruit and Vegetable Flavors; John Wiley and Sons: Hoboken, NJ, USA, 2010.

23. Kafkas, E.; Cabaroglu, T.; Selli, S.; Bozdoğan, A.; Kürkçüoğlu, M.; Paydaş, S.; Başer, K.H.C. Identification of volatile aroma compounds of strawberry wine using solid-phase microextraction techniques coupled with gas chromatography-mass spectrometry. Flavour Fragr. J. 2006, 21, 68-71. [CrossRef]

24. Servili, M.; Selvaggini, R.; Taticchi, A.; Begliomini, A.L.; Montedoro, G. Relationships between the volatile compounds evaluated by solid phase microextraction and the thermal treatment of tomato juice: Optimization of the blanching parameters. Food Chem. 2000, 71, 407-415. [CrossRef]

25. Melgarejo, P.; Calín-Sánchez, Á.; Vázquez-Araújo, L.; Hernández, F.; Martínez, J.J.; Legua, P.; Carbonell-Barrachina, Á.A. Volatile Composition of Pomegranates from 9 Spanish Cultivars Using Headspace Solid Phase Microextraction. J. Food Sci. 2011, 76, S114-S120. [CrossRef] [PubMed]

26. Luna, G.; Morales, M.T.; Aparicio, R. Characterisation of 39 varietal virgin olive oils by their volatile compositions. Food Chem. 2006, 98, 243-252. [CrossRef]

27. Vázquez-Araújo, L.; Chambers, E.; Adhikari, K.; Carbonell-Barrachina, A.A. Physico-chemical and sensory properties of pomegranate juices with pomegranate albedo and carpellar membranes homogenate. LWT Food Sci. Technol. 2011, 44, 119-125. [CrossRef]

28. Tripathi, J.; Chatterjee, S.; Gamre, S.; Chattopadhyay, S.; Variyar, P.S.; Sharma, A. Analysis of free and bound aroma compounds of pomegranate (Punica granatum L.). LWT Food Sci. Technol. 2014, 59, 461-466. [CrossRef]

29. Coda, R.; Lanera, A.; Trani, A.; Gobbetti, M.; Di Cagno, R. Yogurt-like beverages made of a mixture of cereals, soy and grape must: Microbiology, texture, nutritional and sensory properties. Int. J. Food Microbiol. 2012, 155, 120-127. [CrossRef] [PubMed]

30. Mousavi, Z.E.; Mousavi, S.M.; Razavi, S.H.; Emam-Djomeh, Z.; Kiani, H. Fermentation of pomegranate juice by probiotic lactic acid bacteria. World J. Microbiol. Biotechnol. 2011, 27, 123-128. [CrossRef]

31. Reis, F.; Alcaire, F.; Deliza, R.; Ares, G. The role of information on consumer sensory, hedonic and wellbeing perception of sugar-reduced products: Case study with orange/pomegranate juice. Food Q. Prefer. 2017, 62, 227-236. [CrossRef] 
32. Kazakos, S.; Mantzourani, I.; Nouska, C.; Alexopoulos, A.; Bezirtzoglou, E.; Bekatorou, A. Production of low-alcohol fruit beverages through fermentation of pomegranate and orange juices with kefir grains. Curr. Res. Nutr. Food Sci. 2016, 4, 19-26. [CrossRef]

33. Singleton, V.L.; Rossi, J. Colorimetry of Total Phenolics with Phosphomolybdic-Phosphotungstic Acid Reagents. Am. J. Enol. Vitic. 1965, 16, 144-158.

34. Miller, N.J.; Rice-Evans, C.A. Spectrophotometric determination of antioxidant activity. Redox Rep. 1996, 2 , 161-171. [CrossRef] [PubMed]

35. Gentile, C.; Reig, C.; Corona, O.; Todaro, A.; Mazzaglia, A.; Perrone, A.; Gianguzzi, G.; Agusti, M.; Farina, V. Pomological Traits, Sensory Profile and Nutraceutical Properties of Nine Cultivars of Loquat (Eriobotrya japonica Lindl.) Fruits Grown in Mediterranean Area. Plant Foods Hum. Nutr. 2016, 71, 330-338. [CrossRef] [PubMed]

36. Schoina, V.; Terpou, A.; Bosnea, L.; Kanellaki, M.; Nigam, P.S. Entrapment of Lactobacillus casei ATCC393 in the viscus matrix of Pistacia terebinthus resin for functional myzithra cheese manufacture. LWT Food Sci. Technol. 2018, 89, 441-448. [CrossRef]

(C) 2018 by the authors. Licensee MDPI, Basel, Switzerland. This article is an open access article distributed under the terms and conditions of the Creative Commons Attribution (CC BY) license (http:/ / creativecommons.org/licenses/by/4.0/). 